\title{
Association of academic stress with sleeping difficulties in medical students of a Pakistani medical school: a cross sectional survey
}

Ahmed Waqas, Spogmai Khan, Waqar Sharif, Uzma khalid, Asad Ali

Introduction: Medicine is one of the most stressful fields of education because of its highly demanding professional and academic requirements. Psychological stress, anxiety, depression and sleep disturbances are highly prevalent in medical students. Methods: This cross-sectional study was undertaken at Combined Military Hospital Lahore Medical College and Institute of Dentistry in Lahore (CMH LMC), Pakistan. Students enrolled in all yearly courses for the Bachelor of Medicine and Bachelor of Surgery (MBBS) degree were included. The questionnaire consisted of four sections: 1) demographics 2) a table listing 34 potential stressors, 3) the 14-item Perceived Stress Scale (PSS-14), and 4) the Pittsburgh Quality of Sleep Index (PSQI). Logistic regression was run to identify associations between group of stressors, gender, year of study, student's background, stress and quality of sleep. Results: Total response rate was 93.9\% (263/280 respondents returned the questionnaire). The mean (SD) PSS-14 score was 30 (6.97). Logistic regression analysis showed that cases of high-level stress were associated with year of study and academic-related stressors only. Univariate analysis identified 157 cases with high stress levels (59.7\%). The mean (SD) PSQI score was 8.1 (3.12). According to PSQI score, 203/263 respondents (77\%) were poor sleepers. Logistic regression showed that mean PSS-14 score was a significant predictor of PSQI score (OR 1.99, P<0.05).

Conclusion: We found a very high prevalence of academic stress and poor sleep quality among medical students. Many medical students reported using sedatives more than once a week. Academic stressors contributed significantly to stress and sleep disorders in medical students. 
4 Authors: Ahmed Waqas ${ }^{1}$, Spogmai Khan ${ }^{1}$, Waqar Sharif ${ }^{1}$, Uzma Malik $^{1}$, Asad Ali ${ }^{1}$

5 Affiliated Institute: CMH Lahore Medical College and Institute of Dentistry, Abdul Rehman Road,

6 Lahore Cantt. Pakistan 1

$7 \quad$ Lead \& corresponding author:

8 Ahmed Waqas

9 MBBS student $\left(4^{\text {th }}\right.$-year $)$

10 Email address: ahmedwaqas1990@hotmail.com

11 Phone number: +92-03434936117

12 Address: House \# 733, Street \# 5, Overseas-A, Bahria Town, Lahore, Pakistan

13 Funding support: None

14 Type of article: Original Article

15 Conflict of interest: None

16 Sponsorship: None

17 Disclosure: None

18 Mesh Terms: Medical students, psychology, psychological stress, sleep

19 Original word count: 3154 words

20 Abstract word count: 252 words 
Introduction

22 Medicine is one of the most stressful fields of education because of its highly demanding professional

23

24

25

26 and academic requirements. Extensive medical curricula, frequent examinations and fear of failure are sources of constant stress and anxiety for medical students (1), who may cut short their leisure activities and hours of sleep in order to achieve their desired goals. Several studies have reported a high incidence of stress disorders among medical students. According to a systematic review published in 2006, US and Canadian medical students suffer from a higher incidence of psychological distress, anxiety, depression and suicidal ideation than the general population (2). Sherina et al. reported that $41 \%$ of Malaysian medical students suffered from psychological stress, which correlated directly with depressive symptoms (3). Several studies have reported the prevalence of psychological stress in medical students of different nationalities. Prevalence of stress was reported to be $20.9 \%$ in a Nepali medical school (4), 63.8\% in a Saudi Arabian (5) and 90\% in a Pakistani medical school (6).

Psychological stress among medical students may have deleterious consequences and it further leads to poor academic performance (7), sleep disorders (8), alcohol and substance abuse (9), decreased empathy, poor attitude towards the chronically ill and cynicism (10).

Several studies have also reported poor sleep quality in medical students. Anjum et al. found that the prevalence of disturbed sleep patterns among Pakistani medical students was higher than in their non-medical counterparts (11). Psychological stress is a triggering factor for insomnia and has a bidirectional association with poor sleep quality (12). Thus, it represents a vicious cycle that is associated with adverse mental health consequences in medical students. Poor sleep quality is also associated with dysregulation of the human metabolome (13), high failure rates and poor academic performance (14).

Most of the medical schools in Punjab, Pakistan offer a 5-year-long Bachelor of Medicine and Bachelor of Surgery (MBBS) degree program divided into 2 preclinical years followed by 3 clinical 
45 years. These schools use conventional non-problem-based learning (PBL) teaching methods, which

46 consist of teacher-centered didactic techniques, long lectures, tutorials and practical tasks. Students are

47 frequently assessed with written, oral or practical examinations throughout the year, and each year ends

48 with a final exam held by the University of Health Sciences in Lahore. A passing grade on this exam is

49 necessary to qualify for the next academic year. According to Shah et al., Pakistani medical students

50 who reported academic stressors as often/always were 3.45 times more likely to be suffering from

51 psychological stress than their counterparts reporting a never/sometimes response for it (1).

Several studies have reported the prevalence of stress among medical students in Pakistani.

53 However, the paucity of knowledge on pattern of sleeping difficulties in Pakistani medical students and

54 its association with academic stress warranted this study. This study was designed with two aims: 1) to

55 determine the prevalence of psychological stress and pattern of sleeping difficulties among medical

56 students, and 2) to explore the relationship between academic stressors, psychological stress and poor

57 sleeping habits among medical students.

60 Methodology

61 Study design

62 This cross-sectional study was done at Combined Military Hospital Lahore Medical College (CMH

63 LMC) and Institute of Dentistry, Lahore (Pakistan) after approval by the CMH LMC Research Ethics

64 Committee. Students from all yearly courses of the MBBS degree program were included in this study,

65 which took place from August, 2014 to September, 2014. The sample size required for this survey was

66 calculated as 251 participants for a 95\% confidence level, a 5\% margin of error and a population size

67 of 720 medical students. Students were randomly selected with a stratified sampling technique. First

68 the students were divided into groups based on their year of study. Then random numbers were 
69 generated using computer software. A total of 280 self-administered questionnaires were distributed to

70 potential respondents to ensure an adequate percentage response rate. Written informed consent was

71 obtained from all participants. They were informed about the aims of this study and assured anonymity

72 and that only group-level findings would be reported.

\section{Questionnaire}

75 The questionnaire consisted of four sections: 1) demographics 2) a table listing 34 potential stressors,

76 3) the 14-item Perceived Stress Scale (PSS-14), and 4) the Pittsburgh Quality of Sleep Index (PSQI).

77 The demographics section recorded data for participants' age, gender, year of study, residence and

78 background. The table of potential stressors was taken from a similar study in a Pakistani medical

79 school by Shah et al. (1) and used to obtain data on the frequency and severity of each potential

80 stressor. Frequency was reported as never, rarely, sometimes, often or always, and severity was rated

81 with a Likert-type response scale of increasing severity from 1 to 10. instruments to measure perceived stress. It comprises 7 positively-stated and 7 negatively-stated items, and is scored by reverse coding the negatively-stated items and then summing the scores for all 14 items. The scores range from 0 to 56 with higher scores indicating higher levels of stress.

The fourth section of the questionnaire consisted of the PSQI, a self-rating questionnaire that assesses sleep quality and disturbances during the preceding month. This instrument comprises 19 individual items and yields an overall score ranging from 0 to 21 . Participants who score higher than 5 are considered poor sleepers. It also yields scores on seven other components: subjective sleep quality, sleep latency, sleep duration, habitual sleep efficiency, sleep disturbance, use of sleeping medication and daytime dysfunction (16). 
Data analysis

94 Al data were analyzed in SPSS Inc., Chicago, IL, USA v. 20 software. Frequencies were calculated for

95 demographic variables. Mean PSS-14 scores were calculated and divided into quartiles, then further

96 recoded as a dichotomous variable by combining the upper two quartiles and lower two quartiles (cut-

97 off value $=28$ ). These values were recoded as $1=$ high stress levels and $0=$ low stress levels, as in an

98 earlier study from Pakistan (1). The frequencies of stressors were grouped into dichotomies as follows:

99 Never/rarely/sometimes $=0$ and often/always $=1$. These stressors were also grouped into three

100 domains: psychosocial stressors, academic stressors and health-related stressors. Mean severity of

101 stressors was calculated. Logistic regression was used to identify the determinants of perceived stress.

102 The PSS-14 score was used as a dependent variable and age, year of study, gender, residence,

103 background, psychosocial stressors, health-related stressors and academic stressors were used as

104 independent variables. Response frequencies and percentage were reported for subscales of PSQI.

105 Binary logistic regression was used to identify associations between PSS-14 scores and PSQI global

106 scores (dichotomous variable). Independent sample $\mathrm{T}$ test was run to analyze association between

107 academic stressors (less than often/often and always) and PSQI scores.

108

109 Results

110 Demographic characteristics

111 Total response rate was 93.9\% (263 of 280 respondents returned the questionnaire). Mean age (SD) of

112 respondents was 21.1 years (1.78). The gender distribution of the respondents was 148 women $(56.3$

$113 \%)$ vs. 115 men (43.7\%). Most participants were of Pakistani background (220, 83.7\%) and the

114 remaining 43 respondents $(16.3 \%)$ were of other nationalities. Most of the participants resided off the

115 medical school campus $(161,61.2 \%)$ and the remaining $102(38.2 \%)$ resided in student residence 
116 facilities. The distribution according to year of study was 1 st year 58 (22\%), 2nd year 67 (25.5\%), 3rd 117 year $48(18.3 \%)$, 4th year $45(17.1 \%)$ and 5 th year 45 participants $(17.1 \%)$.

118

\section{Perceived stress}

120 Mean (SD) PSS-14 score was 30 (6.97). According to logistic regression analysis, cases of high-level 121 stress were associated with year of study and academic stressors only (Table 1). Univariate analysis 122 identified a total of 157 cases with high stress levels (59.7\%). Most respondents with high levels of 123 stress were 2 nd-year students $(48,71.6 \%)$ and 5 th-year students $(32,71.1 \%)$, followed by 1 st-year $(29$, $12450 \%)$, 3rd-year (24, 50\%) and 4th-year students (24, 53.3\%).

125

\section{$126 \underline{\text { Stressors }}$}

127 The frequency and severity are shown for academic stressors in Table 2, psychosocial stressors in 128 Table 3, and health-related stressors in Table 4. The frequency of different stressors was reported as 129 often/always by $147(55.9 \%)$ respondents for academic stressors, 45 (17.1\%) for psychosocial 130 stressors, and $48(18.3 \%)$ for health-related stressors.

\section{Quality of sleep}

133 Mean (SD) PSQI score was 8.1 (3.12). According to these scores, 203/263 respondents (77.02\%) were 134 poor sleepers. Logistic regression showed that mean PSS-14 score was a significant predictor of PSQI 135 score (OR 1.99, $\mathrm{P}<0.05)$. During the month preceding the survey, $73(27.8 \%)$ respondents got less than

1365 hours of sleep per day, 233 (88.6\%) reported nighttime disturbances, 97 (36.9\%) poor sleep latency, 137128 (48.7\%) daytime dysfunctioning, 94 (35.7\%) poor sleep quality and 31 (11.8\%) poor sleep 138 efficiency. A few respondents 13 (4.9\%) reported using sedatives more than once a week. 
140 (chi-squared $=5.48, \mathrm{P}<0.05)$. The prevalence of poor quality of sleep among stressed students was

$14182 \%$ (129/157), whereas among non-stressed students, only 69.8\% were poor sleepers. Independent

142 sample T test revealed a significant association in mean scores of PSQI scale and academic stressors.

143 Those students who reported academic stressors as often/always had a higher mean score on PSQI

144 scale than their counterparts who reported academic stressors as Never/sometimes (Mean difference=

$1451, \mathrm{P}<.05)$

\section{Discussion}

150 Our sample consisted of medical students enrolled at a privately financed Pakistani medical school

151 which favors a strictly teacher-centered, non-PBL conventional teaching environment. Our results

152 document a high prevalence of psychological stress (59.7\%) and poor sleep quality (77\%), which is in

153 consonance with earlier studies conducted in Pakistan. Most of the respondents (55.9\%) indicated that

154 they often or always experienced academic stressors, and this subgroup was 2.5 times as likely to

155 suffer from psychological stress and poor sleep quality as their non-stressed counterparts. These results

156 underscore the importance of nurturing a positive learning environment for medical students.

158 likely to experience stress and sleep disturbances. This result is consistent with a report by Cohen and

159 colleagues, who found no significant association between stress levels and gender in a sample of

160 college students (15). In 2004, a systematic review of anxiety and depression in the general community

161 reported a higher prevalence of depression in women (mean point prevalence 45.5\%) than in men (17).

162 Similarly, according to Shah and colleagues, female medical students were more likely to experience 
163 stress than male medical students (1). Our study was based at a privately financed medical school,

164 where most of the medical students belong to higher socioeconomic classes and might be assumed to

165 come from a more tolerant cultural background. Therefore, these students might not be exposed to the

166 same psychosocial stressors as students from a more gender-sensitive and patriarchal environment.

167 Medical students enrolled in their 2nd and 5th (final) year of the MBBS program experienced higher

168 levels of stress. This might be due to the extensive teaching curriculum in the 2 nd year, and due to the

169 introduction of clinical subjects and clerkships in the final year of the MBBS degree program.

170 Another interesting finding in our study was that $77 \%$ of the medical students reported poor

171 sleep quality, which was significantly associated with academic stressors. A high percentage of

172 respondents (27.8\%) got less than 5 hours of sleep per night. This is in consonance with a large-scale

173 study of 2515 Ethiopian university students, $55.8 \%$ of whom reported poor sleep quality. That study

174 also reported a strong association between poor sleep quality, stress, anxiety and depression (8). Drug

175 misuse to induce sleep was reported by $4.9 \%$ of the students. Zafar et al., in their survey of four

176 universities in Karachi, Pakistan, found a high prevalence of self-medication by students. More than 33

$177(7.6 \%)$ of their participants reported insomnia as a reason for self-medication, and $44(10 \%)$

178 participants admitted to the misuse of sleeping pills (18). The relatively high use of sleep-inducing

179 medication may have been related with the fact that Pakistani pharmacies sell these drugs without a

180 prescription. According to a 2005 survey, an alarming proportion of Pakistani pharmacies (50/311,

181 16.1\%) reported selling this type of medication without a prescription (19). Our analysis showed that

$18294(35.7 \%)$ respondents complained of daytime sleepiness. People with daytime sleepiness because of

183 insomnia have lower self-esteem and are three times as likely to be involved in road accidents as their

184 well-rested counterparts (20).

185 Our results are consistent with previous studies at medical schools in Nepal (4) and Pakistan (1)

186 that reported a strong association between academic stressors and psychological morbidity. Both of the 
187 schools involved in those studies had a conventional teaching environment. However, the stress

188 associated with a conventional teaching environment can be reduced. The ultimate aim of medical

189 education should be to produce competitive but compassionate, reflective, self-reliant and empathetic

190 doctors. But the stressful environment of medical schools leads to "hardening of [the] heart during

191 medical school" i.e. a decline in the capacity of medical students to empathize (21). Due to academic

192 stress together with high academic and professional expectations, medical students also report suicidal

193 ideation during their school years (22). But these statistics might be underreported in Pakistan because

194 of public stigma revolving around psychiatric illnesses in medical students (23). To address this grave

195 situation, effective screening for psychological stress, anxiety and depression in medical students,

196 along with psychotherapeutic and educational interventions, should be introduced at Pakistani medical

197 schools. Long-term plans should be devised to introduce changes in the medical curriculum to make it

198 less rigid and burdensome on students. New teaching methods should be implemented at Pakistani

199 medical schools to make the learning environment more student-friendly and enjoyable. There is

200 overwhelming evidence that students in the Indian subcontinent perceive positively and welcome PBL

201 methods. A study that compared perceptions towards PBL experiences reported that medical students

202 found these approaches to be better at enhancing team work, interpersonal relationships, motivation

203 and personal enjoyment, and at favoring positive attitudes towards information-gathering, reasoning

204 and independent thinking (24). Students in a PBL curriculum reported better quality of life, perhaps

205 because of the spare time available for self-study and the greater freedom and autonomy to manage

206 their time (25). A randomized controlled trial concluded that mindfulness-based stress reduction

207 programs resulted in mental well-being and improved quality of life in medical and psychology

208 students (26). In their meta-analysis, Shapiro et al. provided overwhelming evidence of improvement

209 in the psychological well-being of medical students who underwent stress reduction programs such as

210 mindfulness-based stress reduction, hypnosis, desensitization, progressive muscle relaxation, social 
211 support and group therapy (27). Such programs also improve participants' spirituality, empathy, 212 positive coping skills and conflict resolution skills (27). Studies should be done to determine the

213 feasibility of campus-based psychological support, stress reduction and relaxation-based interventions 214 such as mindfulness training at Pakistani medical schools.

215 The cross sectional design of this study limits inferences about causality and temporality between 216 academic stressors, psychological stress and sleeping difficulties. Our sample size consisted of a 217 representative sample of a single medical school. Therefore, these results are not generalizable to 218 whole student population in Pakistani medical colleges. The use of self-administered questionnaires is 219 an important limitation in this study and it may lead to recall bias. Psychological stress and sleeping 220 disturbances were assessed with psychometric instruments which are not completely transposable to 221 the DSM diagnostic criteria for psychiatric illnesses.

\section{Conclusion}

224 Our study revealed a high prevalence of academic stress and poor sleep quality among medical 225 students in Lahore. Many medical students reported using sedatives more than once a week. Academic 226 stressors contributed significantly to perceived stress and sleep disorders.

\section{Acknowledgments}

229 The authors thank Aimen Haider, Shahbakht Ilyas, Sayyedah Khadeeja Bokhari and Asad Abbas, 230 students at CMH Lahore Medical College, for their help with data collection. We also thank K.

231 Shashok (AuthorAID in Eastern Mediterranean) for improving the use of English in the manuscript 


\section{References}

236

237

238

239

240

241

242

243

244

1. Shah M, Hasan S, Malik S, Sreeramareddy CT. Perceived stress, sources and severity of stress among medical undergraduates in a Pakistani medical school. BMC Med Educ [Internet]. 2010 Jan;10:2. Available from:

http://www.pubmedcentral.nih.gov/articlerender.fcgi?artid=2820489\&tool=pmcentrez\&renderty $\mathrm{pe}=$ abstract

2. Dyrbye LN, Thomas MR, Shanafelt TD. Systematic review of depression, anxiety, and other indicators of psychological distress among U.S. and Canadian medical students. Acad Med [Internet]. 2006 May;81(4):354-73. Available from: http://www.ncbi.nlm.nih.gov/pubmed/16565188

3. Sherina MS, Rampal L, Kaneson N. Psychological stress among undergraduate medical students. Med J Malaysia [Internet]. 2004 Jul;59(2):207-11. Available from: http://www.ncbi.nlm.nih.gov/pubmed/15559171

4. Sreeramareddy CT, Shankar PR, Binu VS, Mukhopadhyay C, Ray B, Menezes RG. Psychological morbidity, sources of stress and coping strategies among undergraduate medical students of Nepal. BMC Med Educ [Internet]. 2007;7:26. Available from:

http://www.pubmedcentral.nih.gov/articlerender.fcgi?artid=1951961\&tool=pmcentrez\&renderty $\mathrm{pe}=\mathrm{abstract}$

5. Abdulghani HM, AlKanhal AA, Mahmoud ES, Ponnamperuma GG, Alfaris EA. Stress and its effects on medical students: a cross-sectional study at a college of medicine in Saudi Arabia. J Health Popul Nutr [Internet]. 2011 Oct;29(5):516-22. Available from: http://www.pubmedcentral.nih.gov/articlerender.fcgi?artid=3225114\&tool=pmcentrez\&renderty $\mathrm{pe}=\mathrm{abstract}$

6. Shaikh BT, Kahloon A, Kazmi M, Khalid H, Nawaz K, Khan N KS. Students, stress and coping strategies: a case of Pakistani medical school. Educ Heal. 2004;17:346-53.

7. Stewart SM, Lam TH, Betson CL, Wong CM WA. A prospective analysis of stress and academic performance in the first two years of medical school. Med Educ. 1999;33:243-50.

8. Lemma S, Gelaye B, Berhane Y, Worku A, Williams MA. Sleep quality and its psychological correlates among university students in Ethiopia: a cross-sectional study. BMC Psychiatry [Internet]. BMC Psychiatry; 2012 Jan;12(1):237. Available from: http://www.pubmedcentral.nih.gov/articlerender.fcgi?artid=3554495\&tool=pmcentrez\&renderty pe $=$ abstract

9. Ball S, Bax A. Self-care in medical education: effectiveness of health-habits interventions for first-year medical students. Acad Med. 2002;77:911-7. 
10. Crandall SJ, Volk RJ, Loemker V. Medical students' attitudes toward providing care for the underserved. Are we training socially responsible physicians? JAMA. 1993;269:2519-23.

11. Anjum A, Bajwa MA, Saeed R. Sleep patterns; among medical and non-medical students of university of lahore, 2010-11 Professional Med J. 2014;21(1):148-56.

12. Suchecki D, Machado RB, Tiba PA. Stress-induced sleep rebound: adaptive behavior and possible mechanisms." Sleep (2009); 2(3):151-160.

13. Davies SK, Ang JE, Revell VL, Holmes B, Mann A, Robertson FP, Cui N, Middleton B, Ackermann K, Kayser M, Thumser AE, Raynaud FI, Skene DJ. Effect of sleep deprivation on the human metabolome. Proc Natl Acad Sci U S A [Internet]. 2014 Jul 22;111(29):10761-6; Available from: http://www.ncbi.nlm.nih.gov/pubmed/25002497

14. Curcio G, Ferrara M, De Gennaro L. Sleep loss, learning capacity and academic performance. Sleep Med Rev. 2006 Oct;10(5):323-37 Available from: http://www.ncbi.nlm.nih.gov/pubmed/16564189

15. Cohen S, Kamarck T, Mermelstein R. A global measure of perceived stress. J Health Soc Behav. 1983;24(4):385-96.

16. Buysse DJ, Reynolds CF, Monk TH, Berman S, Kupfer D. The Pittsburgh Sleep Quality Index: a new instrument for psychiatric practice and research. Psychiatry Res. 1989;28:193-213.

17. Mirza I, Jenkins R. Risk factors, prevalence, and treatment of anxiety and depressive disorders in Pakistan: systematic review. BMJ. 2004 Apr 3;328(7443):794.

18. Zafar SN, Syed R, Waqar S, Zubairi AJ, Vaqar T, Shaikh M, Yousaf W, Shahid S, Saleem S. Self-medication amongst university students of Karachi : prevalence, knowledge and attitudes. J Pakistan Med Assoc. 2008;58(4):214-7.

19. Butt ZA, Gilani AH, Nanan D, Sheikh AL, White F. Quality of pharmacies in Pakistan : a crosssectional survey. Int J Qual Healthc. 2005;17(4):307-13.

20. Garbarino S, De Carli F, Nobili L, Mascialino B, Squarcia S, Penco MA, Beelke M, Ferrilla F. "Sleepiness and sleep disorders in shift workers: a study on a group of Italian police officers." Sleep. Sleep. 2002;25(6):648-53.

21. Newton BW, Barber L, Clardy J, Cleveland E, O’Sullivan P. Is there hardening of the heart during medical school? Acad Med [Internet]. 2008 Mar;83(3):244-9. Available from: http://www.ncbi.nlm.nih.gov/pubmed/18316868

22. Hershner SD, Chervin RD. Causes and consequences of sleepiness among college students. Nat Sci Sleep [Internet]. 2014 Jun;6:73-84. Available from: http://www.pubmedcentral.nih.gov/articlerender.fcgi?artid=4075951\&tool=pmcentrez\&renderty $\mathrm{pe}=\mathrm{abstract}$ 
304 23. Waqas A, Zubair M, Ghulam H, Wajih Ullah M, Zubair Tariq M. Public stigma associated with mental illnesses in Pakistani university students: a cross sectional survey. PeerJ. 2014 Dec 16;2:e698. doi: 10.7717/peerj.698. eCollection 2014.

24. Nandi PL, Chan JN, Chan CP, Chan P, Chan LP.Undergraduate medical education: comparison of problem-based learning and conventional teaching . Hong Kong Med J. 2000 Sep;6(3):301-6

25. Tempski P, Bellodi PL, Paro HB, Enns SC, Martins MA, Schraiber LB. What do medical students think about their quality of life? A qualitative study. BMC Med Educ. 2012 Nov 5;12(1):106. Available from: http://www.pubmedcentral.nih.gov/articlerender.fcgi?artid=3527341\&tool=pmcentrez\&renderty pe $=$ abstract

26. De Vibe M, Solhaug I, Tyssen R, Friborg O, Rosenvinge JH, Sørlie T, Bjørndal A. Mindfulness training for stress management: a randomised controlled study of medical and psychology students. BMC Med Educ [Internet]. 2013 Jan [cited 2014 Oct 20];13:107. Available from: http://www.pubmedcentral.nih.gov/articlerender.fcgi?artid=3751423\&tool=pmcentrez\&renderty $\mathrm{pe}=$ abstract

27. Shapiro SL, Shapiro DE, Schwartz GE. Stress management in medical education: a review of the literature. Acad Med [Internet]. $2000 \mathrm{Jul}$;5(7):748-59. Available from: http://www.ncbi.nlm.nih.gov/pubmed/10926029 
335

336

337

338

339

340

341

342

343

344

345

346

347

348

349

350

351

352

353

354

355

356

357

358

359

360

361

362

363

364

365

366

367

368

369 
372

373

374

375

376

377

378

379

380

381

382

383

384

385 


\section{Table $\mathbf{1}$ (on next page)}

Determinants of stress according to logistic regression analysis.

Table 1: Determinants of stress according to logistic regression analysis. $\mathrm{R}^{2}=0.095$ (Cox \&

Snell), 0.128 (Nagelkerke). Model chi-squared value $=26.258(\mathrm{df}=11$ )

Notes: $* \mathrm{P}<0.05 * * \mathrm{P}<0.01$ 
2 Table 1: Determinants of stress according to logistic regression analysis. $\mathrm{R}^{2}=0.095$ (Cox \& Snell),

30.128 (Nagelkerke). Model chi-squared value $=26.258(\mathrm{df}=11)$

\begin{tabular}{|c|c|c|}
\hline Determinants & Odds ratio (OR) & $95 \%$ CI for OR \\
\hline Age & 0.880 & $0.651-1.190$ \\
\hline \\
\hline \multicolumn{3}{|l|}{ Female } \\
\hline & 1.339 & $0.748-2.397$ \\
\hline \multicolumn{3}{|l|}{ Residence } \\
\hline \multirow{2}{*}{$\begin{array}{l}\text { National } \\
\text { International }\end{array}$} & 1 & \\
\hline & 0.914 & $0.508-1.645$ \\
\hline \\
\hline \multirow{2}{*}{$\begin{array}{l}\text { Off-campus } \\
\text { residence } \\
\text { On-campus } \\
\text { residence }\end{array}$} & 1 & \\
\hline & 1.291 & $0.606-2.750$ \\
\hline \multicolumn{3}{|l|}{ Year* } \\
\hline \multirow{5}{*}{$\begin{array}{l}1 \text { st } \\
2 \text { nd } \\
3 \text { rd } \\
4 \text { th } \\
5 \text { th }\end{array}$} & 0.197 & 0.039-.999 \\
\hline & 0.563 & $0.151-2.11$ \\
\hline & 0.291 & $0.086-0.987$ \\
\hline & 0.347 & $0.126-0.957$ \\
\hline & 1 & \\
\hline $\begin{array}{l}\text { Psychosocial } \\
\text { stressors }\end{array}$ & 1.231 & $0.571-2.652$ \\
\hline $\begin{array}{l}\text { Academic } \\
\text { stressors** }\end{array}$ & 2.470 & $1.424-4.284$ \\
\hline $\begin{array}{l}\text { Health-related } \\
\text { stressors }\end{array}$ & 0.818 & $0.389-1.721$ \\
\hline
\end{tabular}

4

5 Notes:

$6 * \mathrm{P}<0.05$

$7 * * \mathrm{P}<0.01$.

8 
Table 2 (on next page)

Frequency and severity of academic stressors

Table 2: Frequency and severity of academic stressors 
2 Table 2: Frequency and severity of academic stressors

\begin{tabular}{|l|l|l|}
\hline Academic stressors & $\begin{array}{l}\text { Often/Always } \\
\text { response, } \mathrm{n}(\%)\end{array}$ & $\begin{array}{l}\text { Severity }(1-\text { lowest } \\
\text { to 10 - highest) }\end{array}$ \\
\hline Exam frequency & $190(73.6)$ & 7 \\
\hline $\begin{array}{l}\text { Academic } \\
\text { performance }\end{array}$ & $148(57.4)$ & 7 \\
\hline Academic curriculum & $125(48.4)$ & 6 \\
\hline $\begin{array}{l}\text { Dissatisfaction with } \\
\text { class lectures }\end{array}$ & $86(33.3)$ & 6 \\
\hline $\begin{array}{l}\text { Unavailability of } \\
\text { learning materials }\end{array}$ & $55(21.3)$ & 5 \\
\hline Becoming a doctor & $106(41.1)$ & 6 \\
\hline Lack of leisure time & $123(47.7)$ & 6 \\
\hline $\begin{array}{l}\text { Competition with } \\
\text { peers }\end{array}$ & $77(29.8)$ & 5 \\
\hline $\begin{array}{l}\text { Performance in } \\
\text { practical }\end{array}$ & $73(28.3)$ & 5 \\
\hline $\begin{array}{l}\text { Lack of special } \\
\text { guidance from faculty }\end{array}$ & $70(27.1)$ & 5 \\
\hline
\end{tabular}


Table 3 (on next page)

Frequency and severity of psychosocial stressors

Table 3: Frequency and severity of psychosocial stressors 
2 Table 3: Frequency and severity of psychosocial stressors

\begin{tabular}{|l|l|l|}
\hline $\begin{array}{l}\text { Psychosocial } \\
\text { stressors }\end{array}$ & $\begin{array}{l}\text { Often/Always } \\
\text { response, } \mathrm{n}(\%)\end{array}$ & $\begin{array}{l}\text { Severity of stressors } \\
(1-\text { lowest to 10- } \\
\text { highest })\end{array}$ \\
\hline $\begin{array}{l}\text { High parental } \\
\text { expectations }\end{array}$ & $137(53.1)$ & 7 \\
\hline Loneliness & $64(24.8)$ & 5 \\
\hline Family problems & $62(24)$ & 5 \\
\hline $\begin{array}{l}\text { Living away from } \\
\text { home }\end{array}$ & $66(25.6)$ & 6 \\
\hline $\begin{array}{l}\text { Political situation of } \\
\text { country }\end{array}$ & $42(16.3)$ & 5 \\
\hline $\begin{array}{l}\text { Relations with } \\
\text { opposite sex }\end{array}$ & $41(15.9)$ & 5 \\
\hline $\begin{array}{l}\text { Difficulty reading } \\
\text { textbooks }\end{array}$ & $51(19.8)$ & 5 \\
\hline $\begin{array}{l}\text { Lack of entertainment } \\
\text { in Lahore }\end{array}$ & $71(27.5)$ & 5 \\
\hline $\begin{array}{l}\text { Difficulty with the } \\
\text { journey back home }\end{array}$ & $45(17.4)$ & 7 \\
\hline $\begin{array}{l}\text { Quality of cafeteria } \\
\text { food }\end{array}$ & $100(38.8)$ & 5 \\
\hline Financial strain & $49(19)$ & 5 \\
\hline $\begin{array}{l}\text { Inability to socialize } \\
\text { with peers }\end{array}$ & $26(10.1)$ & 5 \\
\hline $\begin{array}{l}\text { Living conditions in } \\
\text { student residence }\end{array}$ & $49(19)$ & 5 \\
\hline $\begin{array}{l}\text { Member of fraternity } \\
\text { or sorority }\end{array}$ & $14(5.4)$ & 5 \\
\hline $\begin{array}{l}\text { Lack of personal } \\
\text { interest in medicine }\end{array}$ & $28(10.9)$ & $37(14.3)$ \\
\hline $\begin{array}{l}\text { Adjustment with } \\
\text { roommate }\end{array}$ & 5 \\
\hline
\end{tabular}


Table 4 (on next page)

Frequency and severity of health-related stressors

Table 4: Frequency and severity of health-related stressors 
2 Table 4: Frequency and severity of health-related stressors

\begin{tabular}{|l|l|l|}
\hline $\begin{array}{l}\text { Health-related } \\
\text { stressors }\end{array}$ & $\begin{array}{l}\text { Often/Always } \\
\text { response, } \mathrm{n}(\%)\end{array}$ & $\begin{array}{l}\text { Severity }(1-\text { lowest } \\
\text { to } 10 \text { - highest })\end{array}$ \\
\hline Power failures & $139(53.9)$ & 7 \\
\hline Difficulty sleeping & $101(39.1)$ & 6 \\
\hline Class attendance & $112(43.4)$ & 7 \\
\hline Nutrition & $75(29.1)$ & 6 \\
\hline Exercise & $77(29.8)$ & 6 \\
\hline $\begin{array}{l}\text { Quality of cafeteria } \\
\text { food }\end{array}$ & $85(32.9)$ & 7 \\
\hline Physical disability & $10(3.9)$ & 5 \\
\hline Substance abuse & $16(6.2)$ & 5 \\
\hline
\end{tabular}

3

4 